\title{
WPS3397
}

\section{A Unified Framework for Pro-Poor Growth Analysis}

\author{
B. Essama-Nssah \\ Poverty Reduction Group \\ The World Bank \\ Washington, D.C.
}

\begin{abstract}
Starting with a general impact indicator as an evaluation criterion, this paper offers an integrative framework for a unified discussion of various concepts and measures of propoor growth emerging from the current literature. It shows that whether economic growth is considered pro-poor depends fundamentally on the choice of evaluative weights. In addition, the framework leads to a new indicator of the rate of pro-poor growth that can be interpreted as the equally distributed equivalent growth rate. This is a distribution-adjusted rate of growth that depends on the chosen level of inequality aversion. Illustrations based on data for Indonesia in the 1990s show a strong link between growth and poverty reduction in that country. A decomposition of the observed poverty outcomes reveals the extent to which changes in inequality have blunted the poverty impacts of both growth and contraction. Finally, the results also demonstrate that absolute and relative indicators of pro-poor growth can lead to conflicting conclusions from the same set of facts.
\end{abstract}

Keywords: Pro-Poor Growth, Evaluation, Indonesia, Inequality, Poverty Decomposition. JEL Classification: C15, I32, O53

World Bank Policy Research Working Paper 3397, September 2004

The Policy Research Working Paper Series disseminates the findings of work in progress to encourage the exchange of ideas about development issues. An objective of the series is to get the findings out quickly, even if the presentations are less than fully polished. The papers carry the names of the authors and should be cited accordingly. The findings, interpretations, and conclusions expressed in this paper are entirely those of the authors. They do not necessarily represent the view of the World Bank, its Executive Directors, or the countries they represent. Policy Research Working Papers are available online at http:/lecon.worldbank.org.

\footnotetext{
- The author is grateful to Erwin H.R. Tiongson and Jean-Yves Duclos for their insightful comments, and to Shaohua Chen, Aart Kraay, Michael Lokshin, and Martin Ravallion for very useful discussions.
} 


\section{Introduction}

In the context of the definition of the Millennium Development Goals (MDGs) ${ }^{1}$, the international community has declared poverty reduction a fundamental objective of development, and therefore a metric for assessing the effectiveness of development interventions. A member of a given society is considered poor if his or her standard of living falls short of an acceptable minimum according to prevailing social customs and cultural norms. Economic growth associated with the overall development process is considered a powerful instrument of poverty reduction. Indeed, it has been observed that, on average, richer countries tend to have lower poverty incidence with respect to both income and non-income dimensions (World Bank 2001a). Yet, countries with similar rates of economic growth can differ in terms of achievements in poverty reduction. This raises the general issue of the poverty implications of economic growth. For policy making, one is particularly interested in the identification of growth processes that are favorable to poverty reduction.

Generally speaking, pro-poor growth is economic growth that is favorable to the poor. Current literature provides two basic interpretations of the term "favorable". According to one view, growth is pro-poor if the change in inequality associated with the

${ }^{1}$ These goals are: (i) Eradication of Extreme Poverty and Hunger: Reducing by half the incidence of extreme income-poverty (proportion of people living on less than a dollar a day, and the proportion of people who suffer from hunger; (ii) Achieving Universal Primary Education: ensuring that all boys and girls everywhere are able to complete a full course of primary schooling; (iii) Promoting Gender Equity and Empowering Women: ensuring gender parity in primary and secondary education, preferably by 2005, and eliminating gender disparity at all levels of education by 2015; (iv) Reducing Child Mortality: cut under-five child mortality rate by two-thirds; (v) Improving Maternal Health: reduce by three quarters maternal mortality rate; (vi) Combating Major Diseases: Halting and reversing the spread of major diseases (such as HIV/AIDS and Malaria) that afflict humanity; (vii) Ensuring Environmental Sustainability: integrating the principles of sustainable development into country policies and programs, and reversing the loss of environmental resources; reducing by half the proportion of people who lack access to safe drinking water, and achieving by 2020 significant improvement in the lives of slum dwellers through adequate shelter, secure tenure and access to essential social services; (viii) ) Promoting Good Governance: at local, national and global levels to ensure success in all of the above objectives. 
growth process is such that the incomes of the poor grow faster than those of the nonpoor (Kakwani and Pernia 2000). Alternatively, growth is pro-poor if it leads to poverty reduction for some choice of a poverty measure (Kraay 2004). Ravallion and Chen (2003) thus propose an indicator of pro-poor growth based on the Watts index of poverty, while Son (2004) offers one that is consistent with a class of additive poverty measures. However, Son defines pro-poor growth in terms of the relative component of her indicator. The first interpretation of pro-poor growth relies only on distributional shifts and thus focuses on relative gains while the second is based on absolute gains. Our empirical analysis will demonstrate that these two approaches can lead to conflicting conclusions based on the same observations.

The purpose of this paper is to frame the analytical debate about the concept of pro-poor growth within the logic of social evaluation, based on a framework analogous to the one underlying the study of redistribution with growth by Chenery et al. (1974). These authors argue that the choice of development policies and programs must be based on explicit social objectives. In particular, they recommend that any development intervention be assessed in terms of the benefits it provides for different socio-economic groups. In the context of growth analysis, they assume that the rate of growth of income of each group represents a measure of variation of its economic welfare over the period under consideration. Their index of socio-economic performance is the rate of growth of social welfare defined as a weighted sum of the growth rates of income of all groups.

Fields (1980) also provides a useful framework for assessing how different socioeconomic groups may benefit or lose from economic growth. Within this framework, overall growth is a weighted sum of growth in all sectors of the economy. In 
turn, growth in each sector may be decomposed into one component attributable to the enlargement (or contraction) of the sector, and another related to the enrichment of the sector (meaning an increase in the rewards of the factors engaged in that sector). Overall growth thus involves each of these elements and the interaction among them. Different socioeconomic groups would benefit from the process according to their endowments in productive factors and the extent of their participation. In the end, assessing pro-poor growth is an exercise in social evaluation as it involves a criterion for comparing alternative social states, each characterized by a distribution of living standards within the population.

According to Weiss (1998), evaluation entails the examination and weighing of a phenomenon according to some explicit or implicit yardstick. Any evaluation involves four basic aspects: (1) the identification of the objects of value; (2) the valuation of such objects; (3) the formulation of an overall judgment or an aggregate characterization of a situation; and (4) the ranking of alternatives. In this paper, we focus on income poverty so that the objects of value are represented by the income or expenditure enjoyed by an individual or a household in a given state of the economy. We assume away the valuation issues associated with the observability of such indicators of economic wellbeing. For aggregation and ranking, we start with a general expression of an additively separable social evaluation criterion defined as a weighted sum of individual outcomes. We then analyze the identification of pro-poor growth in terms of a pro-poor choice of social weights. This approach leads us to an integrative framework for considering the various definitions and measures of pro-poor growth presented in the literature. It also leads us to a new indicator of pro-poor growth which is consistent with a variety of social 
evaluation functions. We will show that this indicator is a distribution-adjusted growth rate which may be interpreted as an equally distributed equivalent growth rate.

The outline of the paper is as follows. Section 2 discusses a pro-poor specification of social weights in the evaluation criterion. Section 3 illustrates the analysis with data for Indonesia. It is found that there is a strong link between growth and poverty reduction in Indonesia. Concluding remarks are presented in Section 4.

\section{A Pro-Poor Choice of Social Weights}

\subsection{A General Impact Indicator}

Social evaluation may be viewed as an assessment of individual advantage and social progress. To arrive at an overall judgment on whether economic growth is leading to socially desirable outcomes, we need to aggregate individual situations into an indicator of a social state. To see clearly what is involved, consider the following evaluation criterion where $\mathbf{x}_{\mathbf{k}}$ is the living standard of individual $\mathbf{k}$ :

$$
W(x)=\sum_{k=1}^{n} \omega_{k} x_{k}
$$

In the above expression $\mathbf{x}$ stands for a distribution of the living standards over the entire population and $\omega_{\mathbf{k}}$ is the social weight attached to the outcome of individual $\mathbf{k}$.

Consider the change in the living standard of individual $\mathbf{k}$ following a growth spell between period 0 and period 1. This can be written as: $\Delta \mathbf{x}_{\mathbf{k}}=\left(\mathbf{x}_{1 \mathbf{k}}-\mathbf{x}_{\mathbf{0 k}}\right)$. The overall impact of growth between the two period may be written as:

$$
\Delta W(x)=\sum_{k=1}^{n} \omega_{k} \Delta x_{k}
$$


Assuming that social values do not change between periods, then the impact indicator is equal to a weighted sum of individual impacts. The extent to which this impact is socially desirable depends on the choice of the weights $\omega_{\mathbf{k}}$.

\subsection{Specification of Social Weights}

\section{Minimalist Approach}

One can adopt either a minimalist approach or a full specification of social weights. It is assumed that more well-being is preferred to less both at the individual and social level. If we impose only minimal restrictions on the evaluative weights, then a wide class of evaluation criteria will agree on the social desirability of growth induced changes. Suppose we require only that the evaluative weights be nonnegative. Then any change in individual living standards that would improve the lot of at least one individual, without worsening that of any other individual, would be considered an improvement. This is the Pareto criterion. Any set of constant weights would be acceptable as long as they are nonnegative.

Pareto improvement implies $\Delta \mathbf{x}_{\mathbf{k}} \geq \mathbf{0}$ for all $\mathbf{k}$. This would be achieved if growth improved only the outcome of the best off and left everybody else in the situation quo ante. This demonstrates that, in general, the Pareto criterion is not adequate for povertyfocused evaluation. Therefore, further restrictions must be imposed on the evaluative weights in order to factor in our concern for inequality. However, even in the context of the Pareto criterion one can resort to dominance tests to assess pro-poor growth. Indeed, Ravallion and Chen's (2003) measure of pro-poor growth (the growth incidence curve or GIC) is implied by this criterion. To see this, note that: 


$$
\Delta x_{k} \geq 0 \Leftrightarrow \frac{x_{1 k}}{x_{0 k}} \geq 1
$$

It is well known that the level of expenditure or income in a given distribution is equal to the mean of the distribution times the first-order derivative of the Lorenz curve. This fact allows us to write the above condition in terms of the cumulative distribution $\mathbf{p}$ when individuals are treated symmetrically,.

$$
\Delta x_{k} \geq 0 \Leftrightarrow \frac{\mu_{1} L_{1}^{\prime}(p)}{\mu_{0} L_{0}^{\prime}(p)} \geq 1
$$

where $\mu_{\mathbf{t}}$ and $\mathbf{L}_{\mathbf{t}}^{\prime}(\mathbf{p})$ are respectively the mean of the distribution and the first order derivative of the Lorenz curve at time $\mathrm{t}=0,1$. Defining the growth rate at the $\mathrm{p}^{\text {th }}$ quantile as $\mathbf{g}(\mathbf{p})$, and using the fact that the logarithm is a monotonic transformation, we can write the growth incidence curve as:

$$
g(p)=\gamma+\Delta \ln L^{\prime}(p)
$$

where $\gamma$ is the growth rate of the overall mean of the distribution. This is a distributioncorrected growth rate. The adjustment factor is based on changes in the slope of the Lorenz curve. Expression (2.5) shows that $\mathbf{g}(\mathbf{p})$ will be greater than the growth rate $\gamma$ only if the slope of the Lorenz curve (i.e. $\frac{x}{\mu}$ ) is increasing over time. When the Pareto criterion holds, then $\mathbf{g}(\mathbf{p}) \geq \mathbf{0}$ for all $\mathbf{p}$. In other terms, the cumulative distribution function (CDF) of living standards in the second period lies nowhere above that of the first period $^{2}$. We therefore conclude that poverty in the second period would at most be equal to the level observed in the initial period. If the growth incidence curve is strictly greater than zero, then growth is pro-poor for a wide choice of poverty measures.

\footnotetext{
${ }^{2}$ This relation is known as first-order stochastic dominance.
} 
Ravallion and Chen (2003) propose a measure of the rate of pro-poor growth based on a normalization of the area under the GIC. The measure is called the mean growth rate of the poor. It is equal to the area under the growth incidence curve up to the headcount index, divided by the headcount index. Equivalently, this measure of the rate of pro-poor growth can be computed by multiplying the ordinary growth rate in the mean by an adjustment factor. This adjustment factor translates the extent to which distributional changes have been pro-poor. In particular, the adjustment factor is equal to the ratio of the actual change in the Watts index ${ }^{3}$ of poverty to the change in the same index that would have occurred under distributionally neutral growth. The rate of propoor growth will be higher than the ordinary growth rate when the distributional shifts are poverty reducing. Otherwise, it would be equal or less than the growth rate of the overall mean.

If the GIC switches sign, we can no longer rely on first-order dominance to tell what happened to poverty. Additional value judgments are needed. We may, for instance, use nonnegative weights that put a premium on equality (more equality in the distribution of living standards is preferred to less). One way of implementing this idea is to first rank individuals according to some criterion of social desert in the initial state. We then assign weights in such a way that, of any two individuals the more deserving receives a higher weight. In other terms, social weights are now chosen such that each is nonnegative and adjacent weights satisfy the condition $\left(\omega_{\mathbf{k}-1}-\omega_{\mathbf{k}}\right) \geq \mathbf{0}$. Such an assignment would be consistent with the Dalton (or maximin) principle of transfers.

\footnotetext{
${ }^{3}$ In the case of discrete observations, this index may be computed as: $P_{W}=\sum_{h=1}^{m} w_{h} \log \left(z / x_{h}\right)$, where $\mathrm{w}_{\mathrm{h}}$ stands for the population weight for observation $\mathrm{h}$. Ravallion and Chen (2003) show that the area under the GIC up to the headcount index is equal to minus the change in the Watts index of poverty.
} 
Following Mayshar and Yitzhaki (1995), we write the impact indicator as:

$$
\Delta W(\omega)=\sum_{k=1}^{n} \omega_{k} \Delta x_{k}=\sum_{k=1}^{n-1}\left(\omega_{k}-\omega_{k+1}\right) c m x_{k}+\omega_{n} c m x_{n}
$$

Where the cumulative terms $\left(\mathbf{c m} \mathbf{x}_{\mathbf{k}}\right)$ are equal to: $c m x_{k}=\sum_{i=1}^{k} \Delta x_{i}$. By definition: $\Delta x_{k}=c m x_{k}-c m x_{k-1}$. Thus the change will be desirable (in the sense of a Daltonimprovement) if $\mathbf{c m x}_{\mathbf{k}} \geq \mathbf{0}$ for all $\mathbf{k}$.

This condition is equivalent to the following statement:

$$
\sum_{i=1}^{k} \Delta x_{i} \geq 0 \forall k \Leftrightarrow \sum_{i=1}^{k} x_{1 k} \geq \sum_{i=1}^{k} x_{0 k} \quad \forall k \in\{1,2, \ldots, n\}
$$

For an interpretation of this condition, we recall that the generalized Lorenz curve is defined as:

$$
L(\mu, p)=\mu L(p)=\frac{1}{n} \sum_{k=1}^{j} x_{k}=p \mu_{p} ; L(\mu, 0)=0 ; L(\mu, 1)=\mu
$$

where $\mu_{\mathbf{p}}$ is the mean expenditure (income) of the poorest $\mathbf{p}$ percent of the population. If both distributions cover the same population, we can normalize (2.7) by dividing throughout by $\mathbf{n}$. Thus welfare will improve as we move from the initial distribution to the final one if the generalized Lorenz curve associated with the latter lies nowhere below the former. This condition is known as second-order dominance and underlies the poverty growth curve (PGC), the pro-poor growth indicator proposed by Son (2004).

Based on this expression of the generalized Lorenz curve, a Dalton improvement induced by the growth process may be stated as follows:

$$
\frac{\mu_{1 p}}{\mu_{0 p}}=\frac{\mu_{1} L_{1}(p)}{\mu_{0} L_{0}(p)} \geq 1
$$


Using the logarithm, the poverty growth curve $^{4}$ can be expressed as:

$$
\varphi(p)=\gamma+\Delta \ln L(p)
$$

This expression says that the rate of growth of the mean income of the poorest $\mathbf{p}$ percent of the population is equal to the overall growth rate adjusted by a distribution-correction factor. In this case, the adjustment factor is based on changes in the whole Lorenz curve.

Son (2004) bases her motivation of this indicator on the poverty implications of second order dominance as stated in Atkinson's (1987) theorem. When the entire generalized Lorenz curve shifts up, all additive poverty measures would indicate a fall in poverty ${ }^{5}$. Thus when $\varphi(\mathbf{p})$ is strictly greater than zero, we know that poverty has fallen. But if in addition this indicator is greater than the growth rate of the overall mean, then inequality has also fallen ${ }^{6}$. This is the only case that Son would declare as pro-poor. Thus, she effectively bases her assessment only on the relative component of her indicator (namely, shifts in the Lorenz curve).

\section{Full Specification}

The minimalist approach to the specification of evaluative weights underlying the Pareto and the Dalton criteria leads to a dominance relation between the initial distribution of the living standards and the final one. Dominance criteria provide a

\footnotetext{
${ }^{4}$ This terminology is from Son (2004). Jean-Yves Duclos suggested that it might be more informative to call this the "cumulative income growth curve".

${ }^{5}$ It is known that first-order dominance implies second order dominance, but not the other way around. Also, second-order dominance poverty comparisons may be based on TIP curves (Jenkins and Lambert 1997).

${ }^{6}$ In the case of the growth incidence curve, Ravallion and Chen (2003) observe that if $g(p)$ is a decreasing function of all $\mathrm{p}$ in its domain of definition, then all inequality measures that respect the Pigou-Dalton principle of transfers will show a decline in inequality.
} 
general framework for unambiguous assessment of pro-poor growth. Since dominance does not necessarily hold among all possible states, we conclude that it is a partial ordering. For instance, we can no longer invoke dominance if the relevant concentration or Lorenz curves do cross. Further restrictions need to be imposed on the evaluative weights. For instance, one can assign a unique set of values to these weights and thus uniquely determine the evaluative criterion.

One practical way of choosing evaluative weights is to use the cumulative distribution induced by the ranking of individuals according to their initial level of living. Let $\mathbf{p}_{\mathbf{k}}$ represent the proportion of individuals with a living standard less than or equal to $\mathbf{x}_{\mathbf{k}}$. In the context of a large population of individuals, the likelihood of drawing at random a person with a resource endowment higher than that of $\mathbf{k}$ is equal to $\left(\mathbf{1}-\mathbf{p}_{\mathbf{k}}\right)$. This likelihood, also known as the survivor function, declines monotonically from 1 to zero as we move from the lowest to the highest ranking individual ${ }^{7}$. This pattern is consistent with a Dalton distribution of social weights. Given that the mean of the cumulative distribution is equal to 0.5 , we can select normalized weights, $\omega_{k}=2\left(1-p_{k}\right)$. More generally, these weights may be written as (Yitzhaki 1983):

$$
\omega_{k}(v)=v\left(1-p_{k}\right)^{v-1}
$$

where $v$ is to be interpreted as an indicator of aversion for inequality. When the cumulative distribution function $\mathbf{p}_{\mathbf{k}}$ varies from 0 to 1 , the survivor function $\left(\mathbf{1}-\mathbf{p}_{\mathbf{k}}\right)$ varies from 1 to 0 . Hence the weights will decline from $v$ to 0 . In other terms, the criterion assigns the highest weight to the worse off individual and the lowest weight to the best off.

\footnotetext{
${ }^{7}$ This is so because the cumulative distribution function increases monotonically form zero to one.
} 
To better understand the pattern of the distribution of weights associated with specific values of the aversion parameter, we consider the first and second-order derivatives of $\omega_{\mathbf{k}}(v)$ with respect to $\mathbf{p}_{\mathbf{k}}$. These are respectively:

$$
\frac{\partial \omega_{k}(v)}{\partial p_{k}}=-v(v-1)\left(1-p_{k}\right)^{v-2}
$$

and

$$
\frac{\partial^{2} \omega_{k}(v)}{\partial p_{k}^{2}}=v(v-1)(v-2)\left(1-p_{k}\right)^{v-3}
$$

When $\mathbf{v}=\mathbf{1}$, all weights are constant and equal to 1 . Both derivatives are equal to zero, making social evaluation indifferent to inequality. When the aversion parameter is equal to 2 , the slope of the weight function is constant and equal to -2 . Thus, evaluative weights decline monotonically from 2 to zero. The individual with the median income $\left(\mathbf{p}_{\mathbf{k}}=\mathbf{0 . 5 0}\right)$ gets a weight of one. All persons ranked ahead of the median receive a weight greater than one but less than 2. Any individual past the median gets a weight between one and zero (the weight of the least deserving individual or the richest is 0 ).

The monotonic behavior of these evaluative weights with respect to $\mathbf{p}_{\mathbf{k}}$ allows us to define a cut-off rank such that people whose rank is less than the cut-off point receive a weight greater than one but at most equal to $v$. The person at the cut-off rank receives a weight equal to one (the Pareto solution). Any other individual gets a weight less than one (the best off individual gets a weight of zero). Table 2.1 shows such cut-off ranks for a range of values of the aversion parameter. These cut-off points are solutions to the following equation:

$$
v(1-p)^{v-1}=1
$$


In other terms, $p^{*}=1-\left[\frac{1}{v}\right]^{1 /(v-1)}$

Table 2.1. Cut-off Rank as a Function of the Aversion Parameter.

\begin{tabular}{|c|c|c|c|c|c|c|c|c|c|c|c|c|}
\hline$v$ & 1.1 & 1.2 & 1.5 & 2.0 & 3 & 6 & 10 & 20 & 30 & 50 & 100 & 200 \\
\hline $\mathrm{p}^{*}$ & 0.62 & 0.60 & 0.56 & 0.50 & 0.42 & 0.30 & 0.23 & 0.15 & 0.11 & 0.08 & 0.05 & 0.03 \\
\hline
\end{tabular}

These results suggest that the cut-off rank is a decreasing function of the aversion parameter. As this parameter increases, the focus is shifted to the lower end of the distribution. Thus evaluation will attach more weight to the situation of the most deserving group. For instance, when the aversion parameter is equal to 100 , the criterion attaches more weight to the lowest 5 percent of the distribution. An aversion level of 200 shifts the focus of the criterion to the poorest 3 percent of the population. These results also make it obvious that the aversion parameter allows one to calibrate the poverty focus of the evaluation.

We can now use the structure of the impact indicator defined by expression (2.2) to derive a measure of the rate of pro-poor growth as a weighted sum of points on the growth incidence curve ${ }^{8}$. This measure, $\theta(v)$, is a function of the focal parameter, $v$.

$$
\theta(v)=\sum_{k=1}^{n} \omega_{k}(v) \Delta \ln x_{k}=v \sum_{k=1}^{n}\left(1-p_{k}\right)^{v-1} \Delta \ln x_{k}
$$

Using the definition of the covariance between two variables, we can write the rate of pro-poor growth in a form analogous to the expressions presented above for points on the GIC or the PGC. It is equal to the average growth rate $\gamma^{*}$ plus a covariance-based distribution correction factor.

$$
\theta(v)=\gamma^{*}+v \operatorname{cov}\left[\Delta \ln x,(1-p)^{v-1}\right]
$$

\footnotetext{
${ }^{8}$ As indicated earlier, Chenery et al. (1974) propose a similar indicator on the basis of a semi-logarithmic social evaluation function of the form: $W(x)=\sum_{k=1}^{n} \beta_{k} \log x_{k}$. The associated impact indicator is thus a weighted sum of individual growth rates. They suggest the following rules for the specification of evaluative weights. Assign weights either in proportion to the number of people in each group ("one man one vote" principle) or inversely proportional to their initial incomes ("poverty weights").
} 
The covariance term (or distribution correction factor) would vanish, if the focal parameter $v$ were equal to one. This would mean that society does not care about inequality in the distribution of individual outcomes. This puts us back in the domain of Pareto evaluation.

Alternatively, the covariance term would also vanish if all incomes or expenditures grew at the same rate. In this case growth would be distributionally neutral, and the rate of prop-poor growth would be equal the average growth rate. When growthinduced distributional changes are favorable to the poor, this indicator would show a rate of pro-poor growth greater than the average growth rate ${ }^{9}$.

To find an interpretation for this indicator, we factor out the average growth rate and express the measure as follows:

$$
\theta(v)=\gamma *\left[1-C_{\Delta \ln x}(v)\right]
$$

where $C_{\Delta \ln x}(v)=-\frac{v}{\gamma^{*}} \operatorname{cov}\left[\Delta \ln x,(1-p)^{\nu-1}\right]$ is the extended concentration coefficient of individual growth rates. Thus, we call $\theta(v)$ the equally distributed equivalent growth rate. By analogy to the concept of equally distributed equivalent income (Atkinson 1970), this is the growth rate that would be socially equivalent to the observed one, for some choice of the focal parameter, $v$. If all expenditures or income grew at the rate of $\theta(v)$, this would lead to a change in social welfare equivalent to the one induced by the observed pattern of growth. This distribution-corrected average rate of growth allows the analyst to factor in various degrees of aversion for inequality through the focal parameter, $v$.

Finally, it is possible to write this indicator as a function of the growth rate of average expenditure (or income) $\gamma$, in a manner that is analogous to the other indicators discussed above. Using the definition of the growth incidence curve given by (2.5), we get the following equivalent expression.

\footnotetext{
${ }^{9}$ If individual growth rates are declining from the poorest to the richest, then there will be a positive association with the social weights and the covariance term will be positive.
} 


$$
\theta(v)=\gamma+\sum_{k=1}^{n} \omega_{k}(v) \Delta \ln L^{\prime}\left(p_{k}\right)
$$

In the above expression, the distribution adjustment factor is equal to a weighted average of changes in the slope of the Lorenz curve. An assessment based uniquely on the distributional factor in (2.16) or (2.18) would be consistent with Kakwani and Pernia (2000) interpretation of pro-poor growth. Accordingly, growth would be considered propoor only when the distributional factor is positive.

\section{Poverty Implications of Economic Growth in Indonesia}

\subsection{The Era of Sustained Growth and Poverty Reduction}

Indonesia has a long history of high achievements in growth and poverty reduction, even in the face of adverse conditions. In the $1980 \mathrm{~s}$, the country suffered a serious deterioration in its terms of trade with the rest of the world. In particular, the price of oil (one of Indonesia's main exports and source of government revenue) fell by 63 percent between 1981 and 1986 (Ravallion and Huppi 1991). The government responded with two devaluations ${ }^{10}$ in 1983 and 1986, and a sweeping reform of budgetary and structural policies. The rate of economic growth slowed down during the adjustment period, but remained positive and above the rate of growth of the population. Poverty continued to decline over the period.

These positive achievements were mainly due to pre-existing conditions and to government commitment to promoting broad-based economic growth and pro-poor implementation of economic reforms (World Bank 1990). The low level of inequality in the distribution of living standards made it possible for modest growth rates in per capita expenditure to lead to substantial poverty reduction. In the 1970 s and early 1980 s, the

\footnotetext{
${ }^{10}$ On March 30, 1983 the rupiah was devalued from 703 to 970 to the US dollar. On September 12, 1986 the price of a dollar was increased from 1,134 to 1,644 rupiahs (World Bank 1990).
} 
development strategy favored the rural economy, and investment in physical and social infrastructure. The implementation of the adjustment program led to gains in economic efficiency and to a more labor-intensive pattern of growth that ensured gains for most workers in lower income groups. In addition, budgetary transfers to local governments were protected while development expenditures were reallocated to sectors, such as agriculture and human resource development, with greatest potential benefit for the poor.

Table 3.1. Distribution of Household Expenditure in Indonesia 1993-2002

\begin{tabular}{llllllllllll}
\hline Year & Mean & $\begin{array}{l}\text { Lowest } \\
\text { Decile }\end{array}$ & 2nd & 3rd & 4th & 5th & 6th & 7h & 8th & 9th & 10th \\
\hline 1993 & 68.54 & 3.88 & 4.80 & 5.68 & 6.59 & 7.59 & 8.70 & 10.09 & 11.97 & 15.13 & 25.57 \\
1996 & 86.62 & 3.57 & 4.39 & 5.20 & 6.05 & 6.99 & 8.08 & 9.44 & 11.34 & 14.63 & 30.31 \\
1999 & 66.17 & 4.01 & 4.95 & 5.83 & 6.69 & 7.62 & 8.63 & 9.87 & 11.55 & 14.40 & 26.45 \\
2000 & 74.21 & 3.98 & 5.24 & 6.08 & 6.88 & 7.72 & 8.70 & 9.89 & 11.56 & 14.35 & 25.60 \\
2002 & 81.84 & 3.64 & 4.77 & 5.57 & 6.35 & 7.20 & 8.20 & 9.53 & 11.45 & 14.78 & 28.51 \\
\hline
\end{tabular}

Source: World Bank Global Poverty Monitoring Database.

Despite the remarkable progress achieved in the 1980 s, poverty reduction and balanced regional development were identified as key challenges facing Indonesia in the 1990s (World Bank 1990). We now review achievements over that decade with reference to the analytical framework discussed above. Table 3.1 contains the data upon which we base our analysis. Each row of the table gives the mean of monthly household expenditures in 1993 Purchasing Power Parity ${ }^{11}$ (PPP) dollars, along with expenditure share of each decile. The year 1993 (our base year) is also the year when Indonesia became a middle-income country according to World Bank's classification.

\footnotetext{
${ }^{11}$ The World Bank 1993 PPP conversion factor is equal to 635.655 rupiahs to a dollar. This is what one would use to convert dollars in local currency in 1993. The local Consumer Price Index (CPI) can then be used to translate these values into values for a year other than 1993.
} 
Figure 3.1. Growth Incidence Curves for Indonesia: 1993-1999

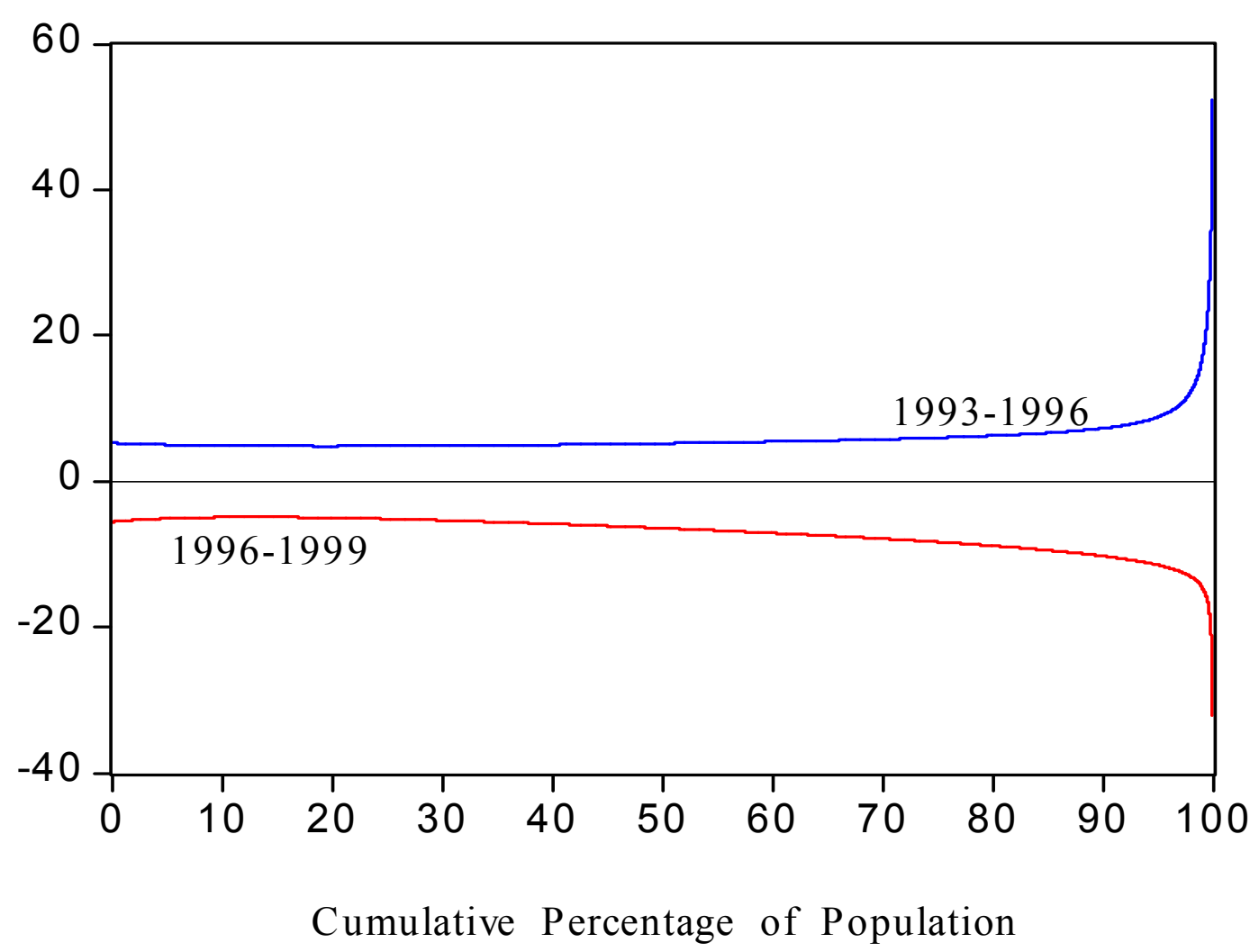

Our analysis is based on the international poverty line of $\$ 65.48$ per person and per month (or \$2.16 per day).

Figures 3.1 and 3.2 present sets of growth incidence curves for the three subperiods: 1993-1996, 1996-1999 and 1999-2002. The fact that the GICs for 1993-1996 and 1999-2002 lie entirely above the zero mark indicates that poverty unambiguously fell between 1993 and 1996, and again between 1999 and 2002. Table 3.2 shows that the proportion of people living below the international poverty line of about 2 dollars a day fell from 61.5 percent in 1993 to 50.5 percent in 1996. 
Figure 3.2. Growth Incidence Curve for Indonesia: 1996-2002

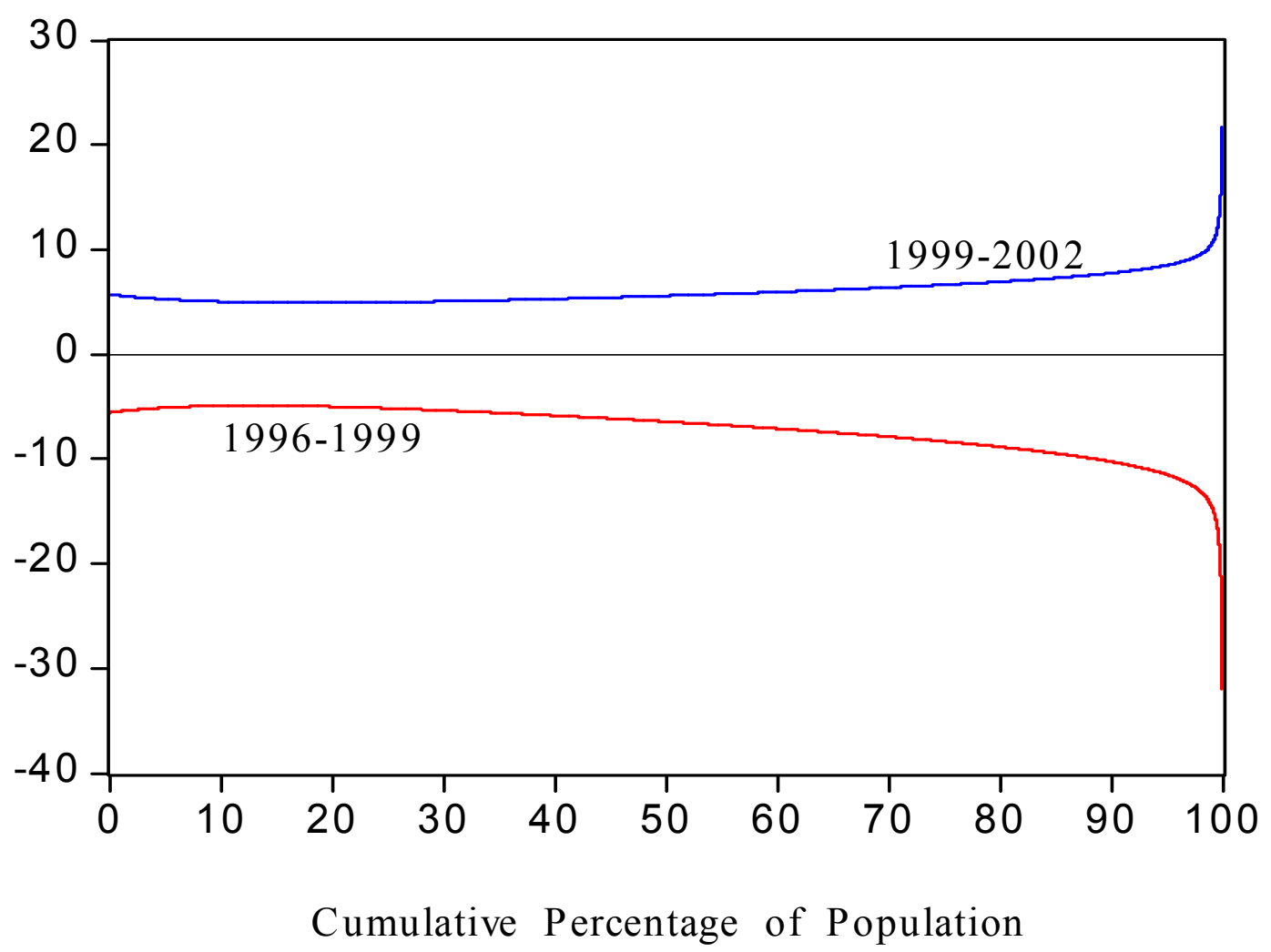

The reduction in poverty experienced by the country between 1993 and 1996 is in fact part of a trend that started in the mid 1980s. Over that period of time, the country successfully adjusted to the oil price shock, the overheating of the economy early in the 1990s, and raised domestic interest rates to protect the rupiah against the contagion effect of the 1995 Mexican crisis (World Bank 1995 and 1996). The induced macroeconomic stability and a well-functioning labor market provided a good foundation to sustained economic growth over the 1984-1996 period, which ultimately led to significant gains in household welfare. The mean per capita monthly expenditure increased in real terms by 
about 52 percent from 17,300 rupiahs in 1984 to 26,300 rupiahs in 1996 (Friedman 2003).

Table 3.2. A Profile of Poverty in Indonesia in the 1990s

\begin{tabular}{lccccc}
\hline Poverty Measures & 1993 & 1996 & 1999 & 2000 & 2002 \\
\hline Headcount & 61.55 & 50.51 & 55.30 & 55.38 & 52.42 \\
Poverty Gap & 21.03 & 15.33 & 16.56 & 16.15 & 15.68 \\
Squared Poverty Gap & 9.16 & 6.02 & 6.49 & 6.23 & 6.09 \\
\hline Source: Computed $^{12}$ & & & & &
\end{tabular}

\subsection{The 1997 Financial Crisis and Its Aftermath}

Both the GICs and the data presented in table 3.2 show a significant increase in poverty between 1996 and 1999. This reversal of the track record of Indonesia in strong growth and poverty reduction is attributed mainly to the 1997 Asian financial crisis. The full impact of this crisis, which hit Southeast Asia in April 1997, began to be felt in Indonesia late in 1997 and early 1998. The crisis took the form of rapid currency depreciation. The exchange rate went from it pre-crisis level of 2,200 rupiahs per dollar in mid 1997 to 6,000 in December of the same year, and then to 17,000 in January 1998 (Pritchett et al. 2002). To avoid a complete collapse of the financial system, the central bank provided a massive liquidity support to banking system while the government offered a guarantee of all its liabilities. Cole and Slade (1998) explain that political factors made this financial crisis much worse and more difficult to deal with. The exchange rate responded more to political perceptions or expectations than to changes in the interest rates.

\footnotetext{
${ }^{12}$ Our empirical analysis is based on a parameterization of the Lorenz curve using the general quadratic model as described in Datt (1998).
} 
The poverty impact of the crisis can be understood in terms of its effects on key determinants of individual livelihood. Indeed, each individual or household in the economy obtains the means of livelihood from market participation and net transfers from the public budgets. The economic contraction induced by the crisis impacted both channels. Gross domestic fixed investment fell by about 35.5 percent in 1998 in real terms. Real GDP declined 13 percent the same year, and resumed positive growth only in 2000 (Strauss et al. 2004). Based on the data presented in table 3.1, we find that real per capita expenditure declined almost 9 percent per year between 1996 and 1999. This decline is consistent with what happened to prices and wages. Currency depreciation and the expansion of money supply fueled price inflation more dramatically for food than for non-food. From February 1996 and February 1999, the price of food increased by 160 percent while the non-food component of the consumer price index (CPI) increased only by 81 percent (Suryahadi et al. 2000). A typical Indonesian household spend about 50 percent of its budget on food (excluding alcohol and tobacco) in the urban areas and about 57 percent in the rural areas. It is estimated that the poor spend between 70 and 80 percent of their entire budget on food (World Bank 2001b). This increase in the relative price of food must have induced a severe deterioration of the welfare of the poor and other net food buyers. The situation was further exacerbated by a major drought that hit the eastern part of Indonesia in late 1997 and the forest fires that occurred during the same period. It is reported that the production of rice fell by 9 percent between 1996 and 1998.

The massive depreciation of the exchange rate implied a substantial change in the relative prices of tradable commodities vis-à-vis non-tradable. As noted by Manning 
(2000), import-intensive activities were the hardest hit by the high rupiah price of imports, in particular those activities producing for the home market. Exports from the manufacturing sectors also fared badly, particularly for those sectors with imported inputs. However, it is believed that small-scale traditional enterprises engaged in importsubstitution activities, and the producers of cash crops for exports may have benefited from this change in relative prices. The construction sector contracted by about 37 percent in 1998. The collapse in investment and the general disruption of economic activity prevented resources from moving out of non-tradables and into tradables as one would expect in the face of a significant devaluation (Manning 2000).

In terms of labor market adjustment, there was a reallocation of rural employment from both tradable and non-tradable into agriculture. A significant contraction of manufacturing employment occurred both in the urban and rural sectors. Nominal wages in both tradable and non-tradable sectors did not keep up with inflation. Thus, overall, real wages fell by 35 percent in 1998, and by close to 40 percent in the manufacturing sector.

Since 1999, the country has made significant progress in restoring macroeconomic stability and external viability, and in reducing the economy's vulnerability (World Bank 2003). On average, real GDP grew 3.2 percent per year between 1999 and 2002. By and large, this has been driven by private consumption boosted by a reduction of interest rates (made possible by low inflation) and a credit expansion. Investment remains some 10 percentage points below its pre-crisis level of 30 percent of GDP. Economic growth performance remains way below the 6 percent that it is believed to be necessary for the country to absorb the 2 million new labor market 
entrants each year (World Bank 2003). Nonetheless, there are encouraging signs on the poverty front. Poverty incidence is heading back to the pre-crisis level (see table 3.2). Still, the majority of the population of this middle-income country live below the international poverty line of 2 dollars a day. It is thus understandable that the government is committed to formulating a comprehensive poverty reduction strategy along the lines of the $\mathrm{PRSP}^{13}$ framework.

\subsection{The Role of Inequality}

Poverty indices are computed on the basis of a distribution of living standards that is fully characterized by the mean and the degree of inequality (as represented by a Lorenz curve). It is therefore reasonable to think of a poverty measure as a function of these two factors. As noted in the introduction, the same growth rate can bring about different levels of poverty reduction. The explanation of this fact can be traced to factors underpinning both the initial level of inequality and its change over time. We now address the counterfactual question of what would have been the poverty outcomes in Indonesia within the three periods considered had inequality not changed within each period. We first briefly describe changes in inequality, and then answer the question based on the Shapley decomposition of poverty outcomes (Shorrocks 1999).

Table 3.3 shows extended Gini coefficients for the last decade. This indicator of inequality is analogous to the extended concentration coefficient defined above. When the aversion parameter is equal to 2 , the extended Gini is equal to the ordinary Gini index. Focusing on this case, we note from table 3.3 that the Gini coefficient increased

\footnotetext{
${ }^{13}$ Poverty Reduction Strategy Paper.
} 
from about 31.7 percent in 1993 to 36.5 in 1996. In 1999, it fell back to the 1993 level. It increased again in 2002 to 34.3 percent. This reveals that inequality increased both before and after the crisis, while it decreased during the crisis.

Table 3.3. Extended Gini Coefficients for Indonesia

\begin{tabular}{cccccc}
\hline Focal Parameter & 1993 & 1996 & 1999 & 2000 & 2002 \\
\hline 1 & 0.00 & 0.00 & 0.00 & 0.00 & 0.00 \\
2 & 31.69 & 36.45 & 31.50 & 30.33 & 34.31 \\
3 & 41.90 & 46.44 & 41.07 & 39.68 & 44.04 \\
4 & 47.16 & 51.41 & 46.05 & 44.63 & 48.96 \\
5 & 50.42 & 54.47 & 49.20 & 47.79 & 52.02 \\
6 & 52.68 & 56.56 & 51.40 & 50.02 & 54.12 \\
\hline
\end{tabular}

Source: Computed

This observation is confirmed by the shape of the GICs and the relative growth incidence curves ${ }^{14}$ (see figures A.1 and A.2 in the annex). The results underlying the relative growth incidence curves reveal the following patterns of growth in relative expenditures. Over the 1993-1996 period, average expenditure grew 7.8 percent per year. Poverty declined even though the expenditure of the poorest 92 percentiles grew at a rate below the overall growth rate. This pattern reversed itself during the crisis. Between 1996 and 1999, mean expenditure declined by almost 9 per year. Poverty increased despite the fact that only the expenditure of the richest 19 percentiles fell faster than the expenditure of the poorest 81 percentiles. This pattern was also observed by Kraay (2004). The pattern of growth in the 1999-2002 period is similar to the one observed in the pre-crisis period. Average expenditure grew about 7 percent a year. Poverty declined, but the distributional shifts favored the non-poor (the corresponding relative

\footnotetext{
${ }^{14}$ A relative growth incidence curve is a graphic representation of the pattern of growth in relative living standard (Kraay 2004). Our curves are obtained by plotting changes in the slope of the Lorenz curve i.e. the second term in the definition of the GIC given by expression (2.5). The relative growth incidence curve may thus be written as: $g_{r}(p)=\Delta \ln L^{\prime}(p)=g(p)-\gamma$. A downward sloping curve indicates a propoor pattern of relative growth. When the curve is upward sloping, distributional shifts do not favor the poor.
} 
growth incidence is upward sloping). Expenditure of the poorest 81 percentiles grew at a rate below the overall growth rate.

Table 3.4. Distribution Adjustment Factor

\begin{tabular}{cccc}
\hline Focal Parameter & $1993-1996$ & $1996-1999$ & $1999-2002$ \\
\hline 1 & -1.88 & 1.86 & -1.02 \\
2 & -2.64 & 3.04 & -1.64 \\
3 & -2.78 & 3.45 & -1.82 \\
4 & -2.83 & 3.64 & -1.89 \\
5 & -2.84 & 3.73 & -1.91 \\
6 & -2.84 & 3.79 & -1.91 \\
\hline
\end{tabular}

Source: Computed

Table 3.4 shows the distribution correction factors associated with the rate of propoor growth defined by equation (2.18). These factors depend on the focal parameter $v$ and are computed as a weighted average of points on the relative growth incidence curve. These factors adjust the overall growth rate up or down according to the pattern of inequality and the degree of aversion to inequality. When the pattern of distributional shifts is favorable to the poor (as was the case during the crisis), the adjustment factor would be positive. Otherwise, it would be negative. After adjustment, we get the rates of pro-poor growth presented in table 3.5. When the focal parameter is equal to 1 , the rate of pro-poor growth is equal to the average growth rate within the population (and not the growth rate of the mean). For instance, between 1993-1996, mean expenditure grew at a rate of 7.8 percent per year. The adjustment factor for $v=\mathbf{1}$, is equal to -1.88 percent. Hence the average growth rate was 5.92 (i.e. 7.8-1.88).

Finally, these results clearly demonstrate the difference between the relative and the absolute interpretation of the concept of pro-poor growth. As we noted earlier, the relative approach would declare growth pro-poor if the associated distributional shifts are favorable to the poor. Thus the relative incidence curve is an indicator of pro-poor 
growth in this relative sense, and so is the distribution adjustment factor reported in table 3.4. According to this view, the 1997 financial crisis was pro-poor in Indonesia despite the observed increase in poverty. Similarly, the relative view would lead us to conclude that growth was not pro-poor in 1993-1996 and 199-2002 despite the note decline in poverty.

Table 3.5.Equally Distributed Equivalent Growth Rates

\begin{tabular}{cccc}
\hline Focal Parameter & $1993-1996$ & $1996-1999$ & $1999-2002$ \\
\hline 1 & 5.92 & -7.12 & 6.06 \\
2 & 5.16 & -5.93 & 5.44 \\
3 & 5.02 & -5.53 & 5.26 \\
4 & 4.98 & -5.34 & 5.20 \\
5 & 4.96 & -5.24 & 5.18 \\
6 & 4.96 & -5.19 & 5.17 \\
\hline
\end{tabular}

Source: Computed

To answer the question of what the poverty outcomes would be under distributional neutrality, we compute the Shapley contributions of growth and inequality to change in poverty. The Shapley decomposition is based on the microeconomic approach to distributive justice where the key issue is a fair assessment of the productive contributions of partners in a joint venture (Moulin 2003). Essentially, the Shapley value of a participant is the solution to a cooperative game. The following definition of the Shapley value is given by Young (1994: 92), in the case of a cost-sharing problem.

"Given a cost-sharing game on a fixed set of players, let the players join the cooperative enterprise one at a time in some predetermined order. As each player joins, the number of players to be served increases. The player's cost contribution is his net addition to cost when he joins, that is, the incremental cost of adding him to the group of players who have already joined. The Shapley value of a player is his average cost contribution over all possible orderings of the players." 
To see how the above principle translates into the decomposition procedure proposed by Shorrocks (1999), consider an aggregate statistical indicator such as the overall level of poverty or inequality. Let it be a function of $\mathbf{m}$ contributory factors which together account for the value of the indicator. The decomposition approach is based on the marginal effect on the value of the indicator of eliminating each of the contributory factors in sequence. The method then assigns to each factor the average of its marginal contributions in all possible elimination sequences.

In the case of change in poverty over time, given a fixed poverty line, the level of poverty at time $\mathbf{t}$ is a function of the mean expenditure (or income) and the Lorenz curve, $\mathbf{P}\left(\mu_{t}, \mathbf{L}_{\mathbf{t}}\right)$. The overall change in poverty from period 1 to period 2 is equal to:

$$
\Delta P=P\left(\mu_{2}, L_{2}\right)-P\left(\mu_{1}, L_{1}\right)
$$

With no change in inequality as measured by the first Lorenz curve, this change in poverty would be equal to:

$$
\Delta_{\mu} P\left(\mu, L_{1}\right)=P\left(\mu_{2}, L_{1}\right)-P\left(\mu_{1}, L_{1}\right)
$$

When inequality is measured by the second Lorenz curve, the expression would take the following value:

$$
\Delta_{\mu} P\left(\mu, L_{2}\right)=P\left(\mu_{2}, L_{2}\right)-P\left(\mu_{1}, L_{2}\right)
$$

Similarly, with no change in the mean income, we have the following expressions:

$$
\Delta_{L} P\left(\mu_{1}, L\right)=P\left(\mu_{1}, L_{2}\right)-P\left(\mu_{1}, L_{1}\right)
$$

and,

$$
\Delta_{L} P\left(\mu_{2}, L\right)=P\left(\mu_{2}, L_{2}\right)-P\left(\mu_{2}, L_{1}\right)
$$

If there is no change in inequality, the marginal contribution of growth to change in poverty is given by either one of the following expressions: 


$$
\Delta_{G 1} P=\Delta P-\Delta_{L} P\left(\mu_{1}, L\right)=\left[P\left(\mu_{2}, L_{2}\right)-P\left(\mu_{1}, L_{2}\right)\right]
$$

or

$$
\Delta_{G 2}=\Delta P-\Delta_{L} P\left(\mu_{2}, L\right)=\left[P\left(\mu_{2}, L_{1}\right)-P\left(\mu_{1}, L_{1}\right)\right]
$$

The Shapley contribution of growth to change in poverty is equal to the average of the above marginal contributions.

$$
S_{G}=\frac{1}{2}\left(\Delta_{G 1}+\Delta_{G 2}\right)=\frac{1}{2}\left[P\left(\mu_{2}, L_{2}\right)-P\left(\mu_{1}, L_{2}\right)\right]+\frac{1}{2}\left[P\left(\mu_{2}, L_{1}\right)-P\left(\mu_{1}, L_{1}\right)\right]
$$

Similarly, it can be shown that the Shapley contribution of inequality to change in poverty is equal to:

$$
S_{L}=\frac{1}{2}\left[P\left(\mu_{2}, L_{2}\right)-P\left(\mu_{2}, L_{1}\right]+\frac{1}{2}\left[P\left(\mu_{1}, L_{2}\right)-P\left(\mu_{1}, L_{1}\right)\right]\right.
$$

Expressions (3.8) and (3.9) may also be derived from an approach proposed by Kakwani (1997).

The following value judgments underlie the Shapley decomposition rule: (1) Symmetry or anonymity: the contribution assigned to any factor should not depend on its label or the way it is listed; (2) the rule should lead to exact or additive decomposition; and (3) the contribution of each factor is taken to be equal to its (first round) marginal impact.

The results reported in table 3.6 through 3.8 show that inequality has blunted the poverty impact of growth in Indonesia in the last decade. According to table 3.6, if growth had been distributionally neutral in the 1993-1996 period, the incidence of poverty would have declined by 16 percent instead of 11 percent. Similarly, poverty incidence would have decreased by 6 percent instead of 3 percent. By the same token, 
the pattern of inequality during the crisis period cushioned the poverty impact of the crisis.

Table 3.6.Shapley Decomposition of Poverty Outcomes 1993-1996

\begin{tabular}{lccc}
\hline Measure & Total Change & Growth & Inequality \\
\hline Headcount & -11.04 & -16.05 & 5.01 \\
Poverty Gap & -5.70 & -8.83 & 3.13 \\
Squared Poverty Gap & -3.14 & -4.95 & 1.80 \\
\hline
\end{tabular}

Source: Computed

Table 3.7. Shapley Decomposition of Poverty Outcomes 1996-1999

\begin{tabular}{lccc}
\hline Measure & Total Change & Growth & Inequality \\
\hline Headcount & 4.79 & 10.00 & -5.21 \\
Poverty Gap & 1.23 & 4.97 & -3.74 \\
Squared Poverty Gap & 0.47 & 2.61 & -2.14 \\
\hline
\end{tabular}

Source: Computed

Table 3.8. Shapley Decomposition of Poverty Outcomes 1999-2002

\begin{tabular}{lccc}
\hline Measure & Total Change & Growth & Inequality \\
\hline Headcount & -2.88 & -5.99 & 3.11 \\
Poverty Gap & -0.88 & -2.97 & 2.09 \\
Squared Poverty Gap & -0.40 & -1.55 & 1.15 \\
\hline
\end{tabular}

Source: Computed

\section{Conclusion}

This paper deals with the important issue of identification of pro-poor growth. This is essentially an exercise in social evaluation as it entails a comparison of social states characterized by various distributions of the living standards induced by the growth process. Starting with a general impact indicator defined as a weighted sum of individual impacts, the paper offers an integrative framework for a unified discussion of various concepts and measures of pro-poor growth emerging from the current literature. It is 
shown that whether economic growth is considered pro-poor depends on the choice of evaluative weights.

The framework thus reveals the connection between assessments based respectively on the growth incidence curve, first-order stochastic dominance, and the Pareto criterion. It also shows the relationship between the poverty growth curve, the second-order stochastic dominance test and the Dalton principle of transfers. When these dominance tests fail, the paper shows how to construct an indicator of pro-poor growth that depends on the chosen degree of inequality aversion. The aversion parameter thus defines the poverty focus of the assessment. Like the other indicators of pro-poor growth encountered in the literature, our measure is a distribution-adjusted rate of growth. One expression of this measure adjusts the average growth rate by a factor equal to 1 minus the extended concentration index of individual growth rates, hence its interpretation as equally distributed equivalent growth rate. The alternative expression corrects the ordinary growth rate by adding a weighted sum of all the points on the relative growth incidence curve.

Empirical analysis of data for Indonesia in the 1990s and early 2000s show that economic growth that occurred both before and after the 1997 financial crisis led to poverty reduction and was accompanied by rising inequality. The increase in poverty observed during the financial crisis should be no surprise in light of the strong link between growth and poverty reduction in Indonesia. Fortunately, during that period, the living standards of the poor fell slower compared to the non-poor. A Shapley decomposition of these poverty outcomes reveals the extent to which changes in inequality blunted the poverty impacts of both growth and contraction. These empirical 
results also demonstrate that absolute and relative indicators of pro-poor growth can lead to conflicting conclusions from the same set of facts.

While indicators discussed in this paper can help in the assessment of the extent to which growth is pro-poor, the key policy issue remains the identification of factors that make economic growth more or less pro-poor. After all, the living standard of an individual is an outcome of the interaction between opportunities offered by society and the ability of the individual to identify and exploit such opportunities. Social arrangements, understood as mechanisms to control and coordinate the behavior of participants, are the ultimate determinants of the degree of access people have to social resources and of their ability to transform such resources into well-being. This point is underscored by the political dimension of the Indonesian crisis. In the end, prevailing social arrangements are the key determinants of the extent to which economic growth is pro-poor. They should therefore be part of the evaluation of pro-poor growth. 
Figure A.1. Relative Growth Incidence Curves for Indonesia: 1993-1999

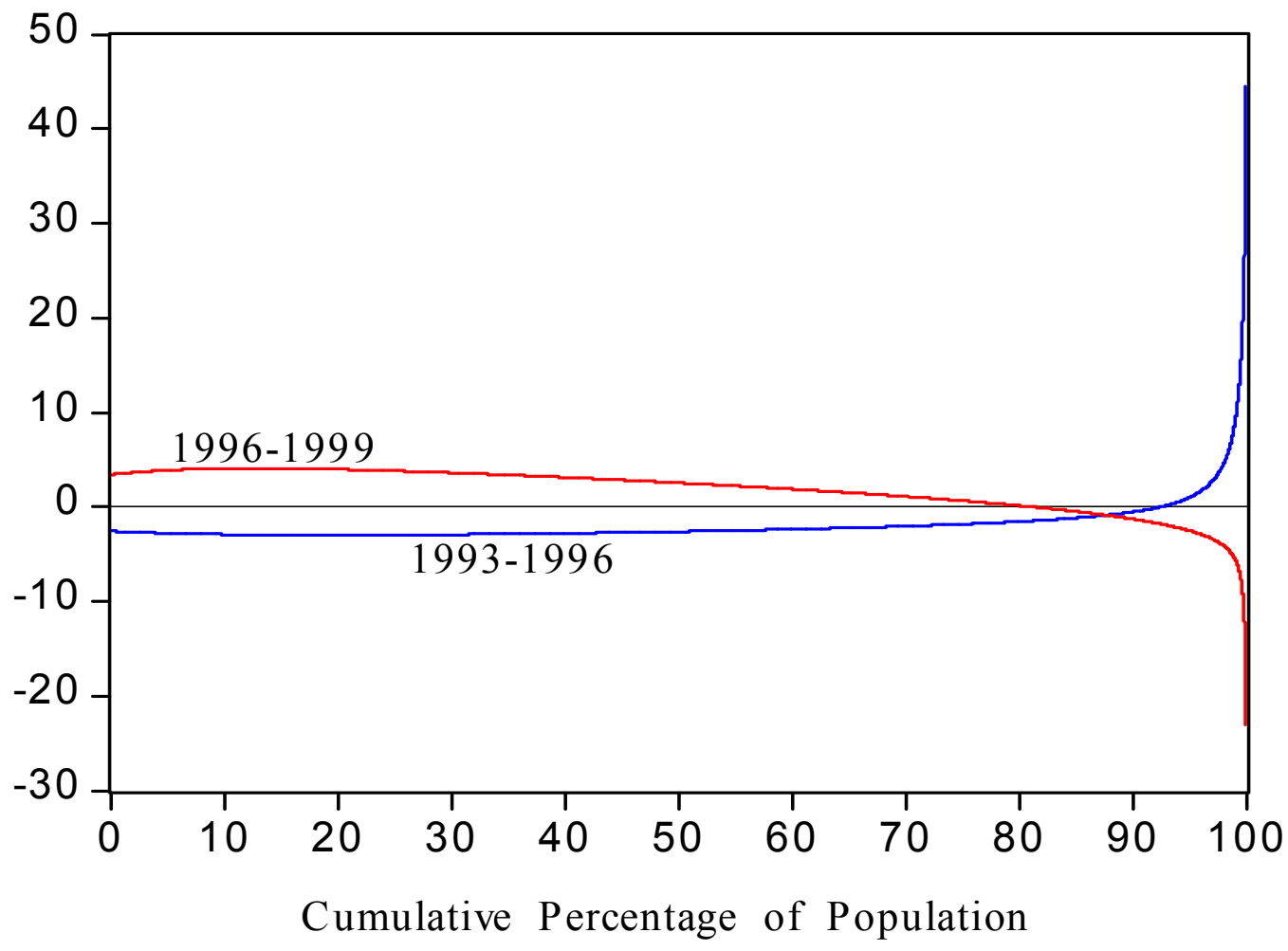


Figure A.2. Relative Growth Incidence Curves for Indonesia: 1996-2002

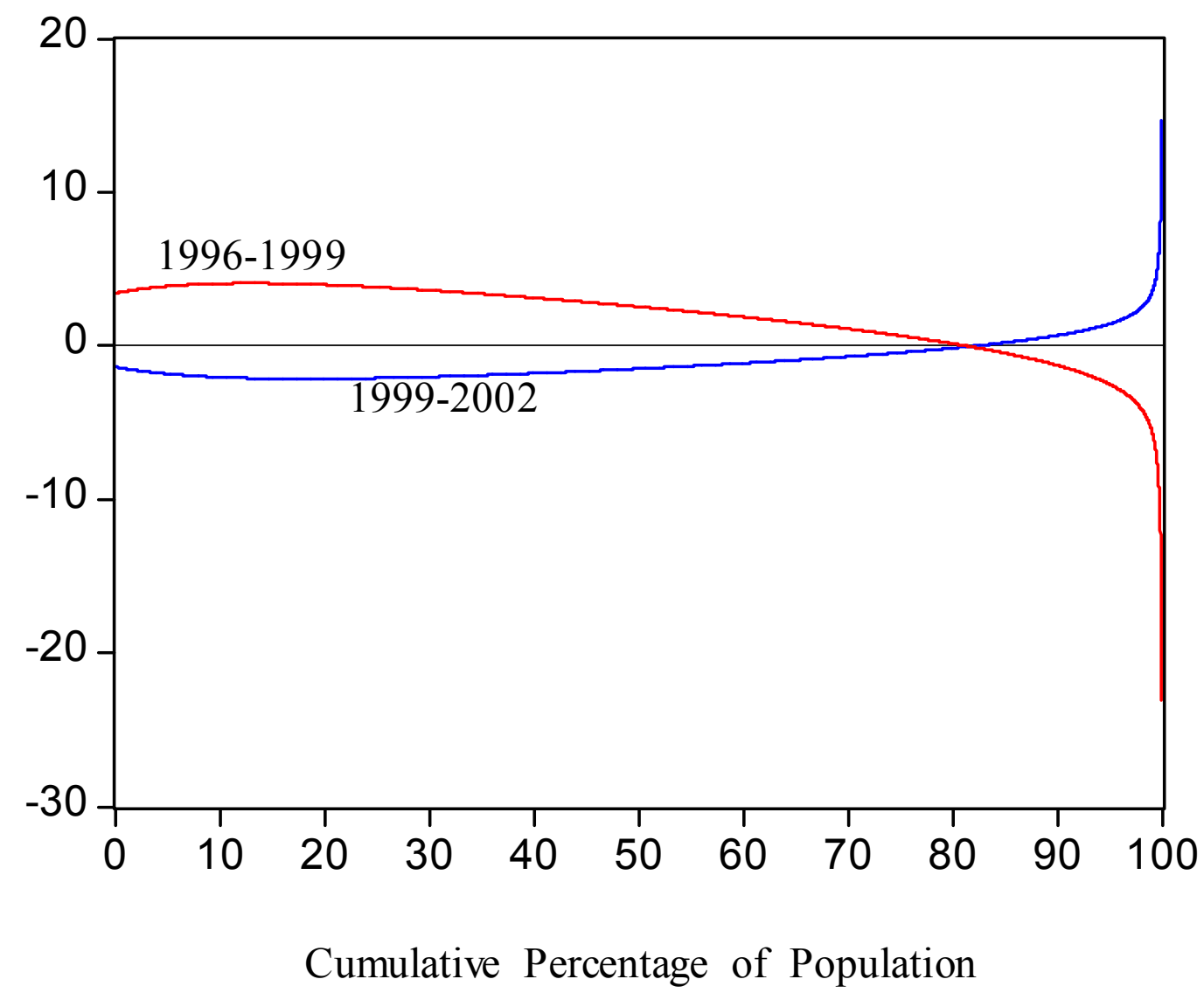




\section{References}

Alatas, Vivi and Bourguignon, François. 2000. The Evolution of the Distribution of Income during Indonesian Fast Growth : 1980-1996. Washington, D.C. The World Bank (mimeo).

Anand, Sudhir and Ravallion, Martin. 1993. Human Development in Poor Countries: On the Role of Private Incomes and Public Services. Journal of Economic Perspectives, Vol.7, No. 1: 133-150.

Atkinson, A. B.1987. On the Measurement of Poverty. Econometrica 55:749-764. . 1970. On the Measurement of Inequality. Journal of Economic Theory, 2, 244-263.

Balisacan, Arsenio M, Pernia, Ernesto M. and Asra, Abuzar. 2003. Revisiting Growth and Poverty Reduction in Indonesia: What do Subnational Data Show? Bulletin of Indonesian Economic Studies, Vol.39, No. 3: 329-351.

Booth, Anne. 2000. Poverty and Inequality in the Soeharto Era: An Assessment. Bulletin of Indonesian Economic Studies, Vol. 36, No.1:73-104.

Chen, Shaohua and Ravallion, Martin. 2004. How Have the World's Poorest Fared since the Early 1980s? Washington, D. C. The Word Bank (mimeo).

Chenery, Hollis, Ahluwalia, Montek S., Bell, C. L. G., Duloy, John H. and Jolly, Richard. 1974. Redistribution with Growth: Policies to Improve Income Distribution in Developing Countries in the Context of Economic Growth. Oxford: Oxford University Press.

Cole, David and Slade, Betty F. 1998. Why Has Indonesia's Financial Crisis Been So Bad? Bulletin of Indonesian Economic Studies, Vol.34, No. 2:61-66.

Datt, Gaurav. 1998. Computational Tools for Poverty Measurement and Analysis. Washington D.C.: International Food Policy Research Institute (IFPRI) Discussion Paper No.50 (Food Consumption and Nutrition Division).

Essama-Nssah, B. 2002. Assessing the Distributional Impact of Public Policy. Policy Research Working Paper 2883. Washington D.C.: The World Bank. . 1997. Impact of Growth and Distribution on Poverty in Madagascar.

Review of Income and Wealth, Series 43, No. 2: 239-251. 
Fields, Gary. 1980. Poverty, Inequality and Development. Cambridge: Cambridge University Press.

Foster J., Greer, J. and Thorbecke, E. 1984. A Class of Decomposable Poverty Measures. Econometrica, Vol. 52, No.3 , 761-766. (May).

Friedman, Jed. 2003. How Responsive is Poverty to Growth: A Regional Analysis of Poverty, Inequality, and Growth in Indonesia, 1984-1999. Helsinki:World Institute for Development Economics Research (WIDER). Discussion Paper No. 2003/57.

, and Levinsohn, James. 2002. The Distributional Impacts of Indonesia's Financial Crisis on Household Welfare: A "Rapid Response" Methodology. The World Bank Economic Review, Vol. 16: No.3: 397-423.

Islam, Rizwanul. 1998. Indonesia: Economic Crisis, Adjustment, Employment and Poverty. Geneva: International Labour Office,. Issues in Development Discussion Paper No. 23.

Jenkins, S. and Lambert, Peter J. . 1997. Three 'I's of Poverty Curves, with Analysis of UK Poverty Trends. Oxford Economic Papers, 49: 317-327.

Kakwani, Nanak. 1999. Inequality, Welfare and Poverty: Three Interrelated Phenomena.

In Jacques Silber (ed.) "Handbook of Income Inequality Measurement". Boston: Kluwer Academic Publishers.

. 1997. On Measuring Growth and Inequality Components of Changes in Poverty with Application to Thailand. Discussion Paper No. 97/16. School of Economics: The University of New South Wales.

. 1993. Poverty and Economic Growth with Application to Côte d'Ivoire. Review of Income and Wealth, Series 39, No. 2: 121-139. , and Pernia, E. 2000. What is Pro-Poor Growth? Asian Development

Review 16 (1): 1-22.

Kolenikov, Stanislav and Shorrocks, Anthony. 2003. A Decomposition Analysis of Reginal Poverty in Russia. World Institute for Development Economics Research (WIDER) Discussion Paper No. 2003/74.

Kraay, Aart. 2004. When is Growth Pro-Poor? Cross-Country Evidence. World Bank Policy Research Working Paper No. 3225. Washington, D.C.: The World Bank.

Mayshar, Joram and Yitzhaki, Shlomo. 1995. Dalton-Improving Indirect Tax Reform. The American Economic Review, Vol. 85, No. 4: 793-807. 
Moulin, Hervé. 2003. Fair Division and Collective Welfare. Cambridge (MA): the MIT Press.

Narayan, Deepa et al. 2000. Voices of the Poor: Can Anyone Hear Us? Washington, D.C.: The World Bank.

Perdana, Ari A. And Maxwell, John. 2004. Poverty Targeting in Indonesia: Programs, Problems and Lessons Learned. Jakarta: Centre for Strategic and International Studies (CSIS) Working Paper No. WPE 083.

Pradhan, Menno, Suryahadi, Asep, Sumarto, Sudarno, and Pritchett, Lant. 2000. Measurements of Poverty in Indonesia: 1996, 1999, and Beyond. Jakarta: Social Monitoring and Early Response Unit (SMERU) Working Paper.

Pritchett, Lant, Sumarto, Sudarno, and Suryahadi, Asep. 2002. Targeted Programs in an Economic Crisis: Empirical Findings from Indonesia's Experience. Cambridge (MA): Harvard University (mimeo).

Ravallion, Martin. 2004. Pro-Poor Growth: A Primer. Policy Research Working Paper No. 3242. Washington, D.C.: The World Bank. . 2001. Growth, Inequality and Poverty: Looking Beyond Averages. World Development Vol. 29, No. 11: 1803-1815.

, 1997. Good and Bad Growth: The Human Development Reports. World Development, Vol. 25, No.5 :631-638. , and Chen, Shaohua. 2003. Measuring Pro-Poor Growth. Fconomics Letters, 78: 93-99.

Ravallion, Martin and Huppi Monika. 1991. Measuring Changes in Poverty: A Methodological Case Study of Indonesia during an Adjustment Period. The World Bank Economic Review, Vol. 5, No. 1:57-82.

Sen, Amartya. 1999. Development as Freedom. New York: Alfred A. Knopf. . 1989. The Concept of Development. In Hollis Chenery and T. N. Srinivasan (eds), "Handbook of Development Economics", Vol. 1. Amsterdam: Elsevier.

Shorrocks, A. F. 1999. Decomposition Procedures for Distributional Analysis: A Unified Framework Based on the Shapley Value. Mimeo, University of Essex. . 1983. Ranking Income Distributions. Economica 50, 1-17. 
Son, Hyun Hwa. 2004. A Note on Pro-Poor Growth. Economics Letters 82: 307-314.

Strauss, John, Beegle, Kathleen, Dwiyanto, Agus, Herawati, Yulia, Pattinasarany, Daan, Satriawan, Elan, Sukamdi, Bondan Sikoki and Witoelar, Firman. 2004. Indonesian Living Standards Before and After the Financial Crisis: Evidence from the Indonesia Family Life Survey. Santa Monica: The Rand Corporation.

Suryahadi, Asep, Sumarto, Sudarno, Suharso, Yusuf and Pritchett, Lant. 2000. The Evolution of Poverty during the Crisis in Indonesia, 1996 to 1999. Policy Research Working Paper No.2435. Washington, D.C.: The World Bank.

Watts, H.M. 1968. An Economic Definition of Poverty. In D.P. Moynihan (Ed), On Understanding Poverty. New York: Basic Books.

Weiss, Carol H. 1998. Evaluation: Methods for Studying Programs and Policies. Upper Saddle River (New Jersey):Prentice Hall.

World Bank. 2003. Indonesia: Development Policy Report, Beyond Macroeconomic Stability. Report No. 27374-IND, Poverty Reduction and Economic Management Unit, East Asia and Pacific Region. Washington, D.C.: The World Bank. .2001a. World Development Report 2000/2001: Attacking Poverty. Washington, D.C.: The World Bank. - 2001b. Poverty Reduction in Indonesia: Constructing a New Strategy, Report No. 2308-IND, Environment and Social Development Sector Unit, East Asia and Pacific Region. Washington, D.C.: The World Bank. . 1990. Indonesia: Strategy for a Sustained Reduction in Poverty. Washington, D.C.: A World Bnak Country Study.

Woo, Wing Thye, Glassburner, Bruce, and Nasution, Anwar. 1994. Macroeconomic Policies, Crises and Long-Term Growth in Indonesia, 1965-90. Washington, D.C. The World Bank.

Yitzhaki, Shlomo. 1983. On an Extension of the Gini Index of Inequality. International Economic Review, Vol. 24, No 3: 617-628.

Young, H. Peyton. 1994. Equity: In Theory and Practice. Princeton: Princeton University Press. 